\title{
An Exploration of Mindfulness Practices and Leadership
}

\author{
Dorothy A. Sisk \\ Lamar University, Beaumont, TX, USA \\ Email:siskda@lamar.edu
}

How to cite this paper: Sisk, D. A. (2018). An Exploration of Mindfulness Practices and Leadership. Creative Education, 9, 1302-1311. https://doi.org/10.4236/ce.2018.99097

Received: March 16, 2018

Accepted: July 9, 2018

Published: July 12, 2018

Copyright (C) 2018 by author and Scientific Research Publishing Inc. This work is licensed under the Creative Commons Attribution International License (CC BY 4.0).

http://creativecommons.org/licenses/by/4.0/

\begin{abstract}
This article explores the use of mindfulness practices in a leadership program, and highlights two major contributors to the development of mindfulness, Thich Nhat Hanh, a Buddhist monk and Dr. Jon Kabat Zinn, a physician. Selected mindfulness programs are reviewed, and a research study integrates mindfulness practices in a leadership program, and the effect of mindfulness practices on student leadership is discussed with results and conclusions.
\end{abstract}

\section{Keywords}

Mindfulness, Well-Being, Wellness, Connectedness, Deep Listening, Gifted

\section{Introduction}

Gandhi's words remind us that we are our own agents of change. Mindfulness is not a new idea since William James in Principles of Psychology (James, 1950) said, "The faculty of voluntarily bringing back a wandering attention, over and over again, is the very root of judgment, character and will." (p. 424). This is mindfulness, and James continued, "an education which should improve this faculty would be the education par excellence" (p. 424). In the Handbook of Leadership, Bass (1981) concluded after a thorough review of leadership literature that there were almost as many definitions of leadership as there were people trying to define the concept. The definition that I find most useful is that of Hakala (2008). He defines leadership as the ability to get others to willingly follow. Hakala identified nine characteristics that demonstrate leadership qualities: integrity, dedication, magnanimity, humility, openness, creativity, fairness, assertiveness, and a sense of humor.

Leaders are people who make things happen and Dorie Shallcross and I wrote a book using behavior of leaders as a title Leadership Making Things Happen 
(Sisk \& Shallcross, 1986). We proposed that leadership was creatively solving problems, and to be able to solve problems one must be self-aware and capable of self-regulation. One transformative strategy in leadership development is mindfulness.

Mindfulness is being aware of what is happening within you and around you with a clear focus of your attention on moment-to-moment experiences in the here and now (Sisk \& Kane, 2017). Gifted students are sensitive and demonstrate great depth in their thinking and feeling, and these characteristics can be positively directed with mindfulness practices. As gifted students engage in mindfulness activities, they can strengthen their inner awareness and leadership. This article will explore mindfulness, mindfulness-based programs and the impact of a research study implementing mindfulness practices on leadership of high ability and gifted secondary students.

Mindfulness has ancient roots; but, incredible applications employing mindfulness are being made daily in medicine, business and education. Two very different people Thich Nhat Hanh, a Vietnamese Buddhist monk and an American medical physician Jon Kabat-Zinn have worked with mindfulness over the last 40 years, with amazing contributions, and their impact on mindfulness will be briefly explored to set the stage for exploring mindfulness practices and leadership development with gifted and high ability students. The first individual to be discussed is Thich Nhat Hanh.

Thich Nhat Hanh is author of five books in the Mindfulness Essential Series including: How to Sit (Hanh, 2014a) with simple directions for exploring mindfulness. The second book How to Relax (Hanh, 2015b) addresses daily stress that makes us less productive and less happy, and Thich Nhat Hanh shares techniques for bringing life back into balance. The third book How to Walk (Hanh, 2015a) reminds us that we touch the Earth with awareness, and the importance of stopping "sleepwalking" to arrive fully in the present moment. The fourth book How to Love (Hanh, 2015c) brings compassion and humor to the essential question of how to love. The fifth book How to Eat (Hanh, 2014b) tells how the process of eating can be a joyful and sustainable activity, including preparing the food, and even cleaning up after a meal. He shares how he and another novice young monk cleaned up after over 100 monks without running water, using sand to clean the dishes, and yet they were able to enjoy the process. In How to Walk (Hanh, 2015a) Thich Nhat Hanh emphasizes love of the Earth, and expressing love of the Earth with each step saying

With each step:

I come home to the Earth

With each step

I return to my source (Hanh, 2015a: p. 114).

Thich Nhat Hanh used the metaphor of a pot looking for a lid to describe the feeling of emptiness or a lack of something, and that we may have a deep thirst for understanding of self and to understand life, or to love and be loved (Sisk \& Kane, 2017). 
The second individual who has made an incredible contribution in mindfulness practice is Jon Kabat-Zinn. He began working with mindfulness in 1979 when he established the Mindfulness-Based Stress Reduction (MBSR) clinic at the Massachusetts Medical Center. Rechtschaffen (2014) in The Way of Mindfulness Education said the word mindfulness was nowhere in the medical lexicon at that time; however, today, over 23,000 certified MBSR instructors teach mindfulness techniques, including meditation. In addition, there are MBSR clinics in nearly every state in the United States, and in more than 30 countries.

Kabat-Zinn began his work with treatment resistant patients of other doctors, and after 8 weeks of mindfulness training, these treatment resistant patients showed remarkable transformation. Symptom reduction was found in blood pressure, psoriasis, and fibromyalgia, and the patients with chronic pain disorder reported a greater sense of well-being (Kabat-Zinn, 1982, 1998). Several randomized controlled trials and studies showed reduction in psychological morbidity and stress, as well as enhanced emotional well-being (Williams, Kolar, Roger, \& Pearson, 2001). Kabat-Zinn said participants in MBSR reported the mindfulness experience as transformative (Kabat-Zinn, 2003).

\section{Sense of Connectedness}

Mindfulness builds a sense of connectedness, and a recognition of the similarities of people. With the growing diversity of the population in the United States, it is essential that we develop a respect and connection with others. One powerful mindfulness activity that positively impacts the need for connection is deep listening. Deep listening involves giving full attention to another person and maintaining a present-centered awareness. High ability and gifted students with their many interests and deep passion for individual projects may find deep listening a challenge. Many of them say they give minimal attention to their teachers until they "hear" something they don't already know or that is of interest to them. This behavior can be problematic in student-teacher interaction. All students can benefit from deep listening not only for academic achievement, but for greater social awareness and ability to get along with others.

Several mindfulness-based programs have been developed to help develop mindfulness in both students and teachers, and these will be explored for their relevance and use in mindfulness practices and leadership development.

\section{Care}

Jennings (2015) an internationally recognized leader in the field of education and a professor from the University of Virginia worked with a team of former teachers and teacher educators to develop a program called the Cultivating Awareness and Resilience in Education (CARE) program. Jennings, Frank, Snowberg, Coccia, \& Greenberg, 2013 reported that teachers who participated in the CARE program improved in well-being, self-efficacy and mindfulness compared to a control group. 
Jennings said engaging in reflection helps build an awareness of the benefit and importance of taking responsibility for building positive interaction.

\subsection{Transformative Life Skills}

Jennifer Frank, a Penn State University professor collaborated with Niroga Institute to develop the Transformative Life Skills (TLS) program that emphasizes mindful yoga, breathing techniques and meditation. This three core practices in TLS are action, breathing and centering. Action includes mindful movement and yoga postures; and the Breathing exercises help individuals manage stress. Centering involves practicing mindfulness and focusing on the present moment. A TLS pilot study with 49 high-risk secondary students found the program reduced student stress and improved their well-being (Frank, Bose, \& Schrobenhauser-Clonan, 2014).

\subsection{Learning to Breathe}

Broderick (2013) developed Learning to Breathe, a program using six themes in the acronym BREATHE. $\mathbf{B}$ is for body awareness, $\mathbf{R}$ is for reflection and working with your thoughts, $\mathbf{E}$ is for understanding and working with feelings, $\mathbf{A}$ is for integrating awareness of thoughts, feelings, and bodily sensations, $\mathrm{T}$ is for tenderness, taking it as it is, and reducing harmful self-judgment of self and others, $\mathrm{H}$ is for habits of a healthy mind, integrating mindful awareness into daily life, and E is for empowerment. Metz, Frank, Reibel, Cantrell, Sanders, \& Broderick (2013) found secondary students engaged in Learning to Breathe reported lower stress levels, negative affect, and psychosomatic complaints, and increased levels of efficacy and emotional regulation.

\subsection{Inner Kids}

Inner Kids was designed by Susan Kaiser-Greenland with a focus on attention, balance and compassion. Participants develop awareness of their inner experiences, thoughts, emotions, and physical sensations; awareness of outer experiences of other people, places and things; and the importance of how these two inner and outer experiences blend together. Flook, Smalley, Kitil, Galla, Kaiser-Greenland, Locke, Ishijima, \& Kasari (2010) used a randomized controlled study involving 64 children ages seven to nine. They randomly assigned the students to either the Inner Kids program or to a control group that received a silent reading period. Compared to the control group, the students in the Inner Kids group showed greater improvement in behavioral regulation, metacognition and overall global executive control compared to the control students (Sisk \& Kane, 2017).

\subsection{Mind Up}

The Hawn foundation created by Goldie Hawn when she lived in Vancouver developed the Mind Up program. The program covers four areas: 1) How Our Brains Work, 2) Sharpening Your Senses, 3) It's All About Attitude, and 4) Tak- 
ing Action Mindfully. MindUp is included in the curriculum of most elementary schools in the southern mainland of British Columbia, Canada, and was adopted by the city of Newark, New Jersey (Sisk \& Kane, 2017). Kimberly Schonert-Reichl, a professor at the University of British Columbia conducted a series of research studies of Mind Up and found that students in the program were more optimistic and self-confident, and their teachers said they demonstrated more social competence (Schonert-Reichl \& Lawlor, 2010).

\subsection{Kripalu Schools}

Kripalu Yoga in Schools (KYSIS) was developed to empower adolescents to learn social and emotional skills such as stress management, emotion and behavior regulation, self-appreciation, self-confidence and relationship skills (Sisk \& Kane, 2017). A pilot study of the KYSIS program was conducted to examine the feasibility of integrating yoga and mindfulness activities into regular high school programming and to test the efficacy of the program in improving well-being. with high school students. An evaluation of the pilot study was conducted by Noggle, Steiner, Minami \& Khalsa (2012). They found the students showed improvement in mood disturbances and lessened anxiety.

\subsection{Exploring Mindfulness Practices with High School Gifted Students}

The Texas Governor's School (TGS) was founded in 1990 as a three-week residential summer leadership program for high achieving and high ability students from throughout the state of Texas at Lamar University in Beaumont, Texas. The staff and director decided to explore and plan the use of mindfulness practices in the program for the 73 students attending the 1917 TGS leadership program, Evidence-based research and suggested activities of five Mindfulness programs (Kripalu Yoga, Mind Up, Breathe, Inner Kids and Transformative Life Skills were implemented. Specific mindfulness activities were selected including Mindful Walking, Awareness Breathing, Belly Breathing, Mindful Movement, Mindful Eating, Visualization and Loving Kindness Meditations to be implemented into the Texas Governor's School.

\subsection{Activities}

Awareness Breathing encourages the students to become aware of their breathing in and out. They breathe in at a count of 1-2-3, hold the breath 1-2-3 and exhale 1-2-3.

Belly Breathing involves the student in placing a stuffed animal or pillow on their stomach and then watching and feeling the animal or pillow rising and falling with each breath (Sisk, 2017b).

Mindful Walking was experienced by the students walking slowly around the track of the University, concentrating on their deep breathing, and paying attention to their senses. The students were reminded to notice what they were hearing, seeing, smelling or feeling as they walked. The following gatha suggested by 
Hanh (2015a) was used:

Breathing in, I am aware of my feet.

Breathing out, I smile at my feet (p. 112).

Mindful Movement engaged the students in learning to use several yoga positions, particularly the Sun Salutation which they experienced with their counselors each morning before breakfast (Sisk, 2017b).

Mindful Eating encouraged the students to savor a raisin by placing it in their mouth for several minutes before finally chewing and swallowing it. Marshmallows were also used with the same intense concentration. One favorite activity of the students was a snack meditation with tangerines in which they slowly and mindfully ate the tangerine as if it were the most important thing for them to do in their life (Sisk, 2017b).

Visualization included several visualizations provided by Dr. Sisk, the Director including the classic Three Boxes developed by Maslow (1968) and the Wise Seer on the Mountain from the book the Growing Person (Sisk \& Shallcross, 1982).

Loving Kindness included a number of Loving Kindness mantras using several of Thich Nhat Hanh's gathas from his five books. A favorite of the students was a gatha from Goldstein (2007):

May I be happy

May I be peaceful.

May I be free from suffering (p. 6).

\subsection{Texas Governor's School Mindfulness Study}

\section{Participants and Methodology}

The Texas Governor's School student participants were high ability and high achieving secondary students ranging in ages from 14 - 18 and they were enrolled in grades 10 - 12. Mindfulness practice sessions were provided daily for 30 minutes Monday through Sunday. Each of the participating students was assigned to an individual counselor who worked with a group of ten to twelve students in a "family". The counselors reinforced the mindfulness practices in evening sessions with their family of students. Observations by the Director and the teaching staff during the mindfulness activities indicated that most students were successfully able to block out any noise or distractions during the mindfulness activities. Dr. Sisk, the Director trained the counselors in the use of the mindfulness practices in a weekend session, and she conducted the visualization sessions. Each of the students maintained a daily reflective journal in which they wrote about their feelings and thoughts following the mindfulness activities. These entries were examined by Dr. Sisk for themes at the end of the three-week session. Four themes emerged including: 1) a feeling of calmness; 2) sensory awareness; 3) enjoyment; and 4) a sense of peace.

\subsection{Instruments}

The students were administered a Mindful Attention Awareness Scale developed 
by Ruth Baer at the University of Kentucky. In addition, the students were also administered a Leadership Skills and Behaviors Scale developed by Sisk and Rosselli (1987). The scale is based on the definition of leaders as creative problem solvers and consists of items for students to self-rate on eight skills including: Decision-making, problem-solving, group dynamics, communicating, organizing, implementing, planning, and discerning opportunities. In addition, there are two items focusing on motivation and positive self-concept. Students respond to the questions using a rating scale of 1 - 5 with Never, Seldom, Sometimes, Often, and Always. Validity and reliability are not provided, but the Leadership Skill and Behavior Scale has been used as pre-post-test measure for a number of three-week residential leadership programs for academically gifted students. In addition, the students, teachers and parents responded to a survey at the end of the three-week session. The survey questions focused on gauging satisfaction of the TGS program, growth in leadership and understanding and use of mindfulness strategies. Most students agreed (45\%) or completely agreed that they felt a sense of satisfaction in the program; and $85 \%$ agreed that their leadership had improved and 15\% completely agreed that their leadership had improved. In response to questions on their awareness and use of mindfulness, $70 \%$ agreed that they understood and use mindfulness activities and $30 \%$ completely agreed that they use mindfulness activities. Students perceived that their leadership had improved. Several students' comments demonstrate their perception of growth in leadership:

Here in the Texas Governor's School I found it was easy for me to take a stand on issues and I chaired several discussion groups. I never did that in my regular School! I know how to be a leader and how to get others to talk and share, and finish our projects.

Another student said:

I surprised myself when I stepped forward and volunteered to lead a discussion or activity and nobody groaned like regular school kids do when someone Volunteers.

In response to their awareness and use of mindfulness activities the students were quite enthusiastic. One student said:

I have trouble going to sleep, my mind just won't turn off and I liked the way Dr. Sisk talked about monkey mind, that's me. When I focus on my breathing, I become calm and drift off. I will use this activity when I get home and I am busy with school and my tennis matches.

Another student said:

At first, when we did body scan, I tried to hurry and my thoughts jumped around, but little by little I calmed my thoughts and felt a sense of rest and peace. I am going to share this with my sister who is really hyper.

The survey questions to the parents basically asked for their satisfaction with the Program mechanisms, application, orientation and enrollment. The results indicated that $85 \%$ of the parents were satisfied and $15 \%$ were completely satisfied. One parent said: 
My son did not call home once during the three weeks, but did drop a few post cards that I had addressed and said, "I am happy" and "I am learning so much about me." I thank you so much for the Texas Governor's School Program for my son.

The teachers were $90 \%$ satisfied with the program and $10 \%$ were completely satisfied. One teacher shared:

I was amazed at how the registration went so smoothly and how the students adapted to a new room-mater and college-life. Some had never been away from Home.

Another teacher said:

This mindfulness was new to me, and frankly I couldn't see its relevance to the leadership focus, but I saw how "squirrely" students calmed down after a Mindufness activity. I also saw how you could also most see them counting 1-2-3. Before responding to comments that were hurtful or even when they were criticized....what a great life skill.

\section{Results}

Mindfulness pre-test scores as measured by the Mindful Attention Awareness Scale were 3.95 and post-test scores were 4.28 . Self-concept as measured by the Leadership Skills and Behaviors Scale indicated 15.33 pre-test scores and post-test scores of 16.92. Motivation as measured by the Leadership Skills and Behaviors Scale pre-test scores were 23.90 and post-test scores were 25.18. Paired $t$ test results showed significant differences in the three test scores of mindfulness, self-concept and motivation at the 0.01 level. The surveys of the students, parents and teachers indicated satisfaction with the program and a growing awareness of student leadership and use of mindfulness activities. The teachers were completely satisfied with the program and indicated that they would be using the leadership and mindfulness activities in their regular classrooms. Most important, they all said they wanted to return in 2018 as teachers in the Texas Governor's School Program.

\section{Conclusion}

Mindfulness strategies can reduce anxiety and stress, and most importantly, they can calm the "monkey mind" of adolescents and encourage them to risk-take being a leader (Siegel, 2014). We found that it was important for the staff, teachers and students to approach the use of mindfulness with an open-heart, present moment, and nonjudgmental awareness. The benefits for both the Texas Governor's School teachers and students were described as truly transformative and life changing. The teachers were able to gain greater understanding of the power and purpose of the teenage brain of high achieving and gifted students by practicing the deep listening activities of mindfulness and the students benefited from the personalized attention to their leadership development. The findings from this exploration support the need to develop the leadership of students and 
to implement mindfulness strategies to help them manage stress and learn to live mindfully. If you want to get more involved in incorporating mindfulness in your life and in your classrooms, it is helpful to connect with others who are trying to do the same thing. The references in this article include websites and resources that can help you get started, and there are free audio recordings of guided mindfulness practices that can be downloaded. Mindfulness practices and programs can truly transform the lives of individuals and students (Sisk, 2017a).

\section{References}

Bass, B. (1981). Handbook of Leadership. New York, NY: Free Press.

Broderick, P. (2013). Learning to BREATHE: A Mindfulness Curriculum for Adolescents to Cultivate Emotion Regulation, attentIon, and Performance. Oakland, CA: New Harbinger.

Flook, L., Smalley, S. L., Kitil, M. J., Galla, B., Kaiser Greenland, S., Locke, J., Ishijima, E., \& Kasari, C. (2010). Effects of Mindfulness Awareness Practices on Executive Functions in Elementary School Children. Journal of Applied School Psychology, 26, Issue 1 .

Frank, J., Bose, B., \& Schrobenhauser-Clonan, A. (2014). Effectiveness of a School-Based Yoga Program on Adolescent Mental Health, Stress, Coping Strategies, and Attitudes toward Violence. Findings from a High-Risk Sample. Journal of Applied School Psychology, 50, 29-49. https://doi.org/10.1080/15377903.2013.863259

Goldstein, J. (2007). A Heart Full of Peace. Boston, MA: Wisdom Publications.

Hanh, T. N. (2014a). How to Sit. Berkeley, CA: Parallax Press.

Hanh, T. N. (2014b). How to Eat. Berkeley, CA: Parallax Press.

Hanh, T. N. (2015a). How to Walk. Berkeley, CA: Parallax Press.

Hanh, T. N. (2015b). How to Relax. Berkeley, CA: Parallax Press.

Hanh, T. N. (2015c). How to Love. Berkeley, CA: Parallax Press.

James, W. (1950). The Principles of Psychology. New York, NY: Dover.

Jennings, P. (2015). Mindfulness for Teachers. New York, NY: W.W. Norton \& Co.

Jennings, P. A., Frank, J. L., Snowberg, K. E., Coccia, M. A., \& Greenberg, M. T. (2013). Improving Classroom Learning Environment by Cultivating Awareness and Resilience in Education (CARE): Result of a Randomized Controlled Trial. School Psychology Quarterly, 28, 374-390.

Maslow, A. (1968). Toward a Psychology of Being. Princeton, NJ: Van Nostrand.

Metz, S., Frank, J., Reibel, D., Cantrell, T., Sanders, R., \& Broderick, P. (2013). The Effectiveness of the Learning to BREATHE Program on Adolescent Emotion Regulation. Research in Human Development, 10, 252-272. https://doi.org/10.1080/15427609.2013.818488

Noggle, J., Steiner, J., Minami, T., \& Khalsa, S. (2012). Benefits of Yoga for Psychosocial Well-Being in a US High School Curriculum: A Preliminary Randomized Controlled Trial. Journal of Developmental \& Behavioral Pediatrics, 33, 193-201.

Kabat-Zinn, J. (1982). An Out-Patient Program in Behavioral Medicine for Chronic Pain Patients Based on the Practice of Mindful Meditation. General Hospital Psychiatry, 4, 33-47. 
Kabat-Zinn, J. (1998). The Effect of Mindfulness-Based Stress Reduction, Mindfulness and Stress Level. In J. C. Holland (Ed.), Psycho-Oncology (pp. 767-779). New York, NY: Oxford University Press.

Kabat-Zinn, J. (2003). Mindfulness-Based Interventions in Context: Past, Present and Future. Clinical Psychology: Science and Practice, 10, 144-156. https://doi.org/10.1093/clipsy.bpg016

Rechtschaffen, D. (2014). The Way of Mindful Education. New York, NY: Norton \& Company.

Schonert-Reichl, K., \& Lawlor, M. (2010). The Effects of a Mindfulness-Based Education Program on Pre and Early Adolescents' Well-Being and Social and Emotional Competence. Mindfulness, 1, 137-151. https://doi.org/10.1007/s12671-010-0011-8

Siegel, D. (2014). Brainstorm: The Power and Purpose of the Teenage Brain. New York, NY: Tarcher. https://doi.org/10.1037/e651052013-077

Sisk, D., \& Rosselli, H. (1987). Leadership Skills \& Behaviors Scale. In Leadership: A Special Type of Giftedness (pp. 102-106). Unionville, NY: Trillium Press.

Sisk, D., \& Shallcross, D, (1982). The Growing Person. Buffalo, NY: Bearly Limited Press.

Sisk, D., \& Shallcross, D. (1986). Leadership: Making Things Happen. Buffalo, NY: Bearly Limited Press.

Sisk, D., \& Kane, M. (2017). Planting Seeds of Mindfulness. New York, NY: Royal Fireworks Press.

Sisk, D. (2017a). Mindfulness and Its Role in Psychological Well-Being. Psychology Research, 7, 530-535.

Sisk, D. (2017b). Mindfulness Practices That Can Be Implemented in the Regular Classroom. Journal of Yoga and Physiotherapy, 2, 1-4.

Williams, K., Kolar, M., Roger, B., \& Pearson, J. (2001). Evaluation of a Wellness-Based Mindfulness Stress Reduction Intervention: A Controlled Trial. American Journal of Health Promotion, 15, 422-432. https://doi.org/10.4278/0890-1171-15.6.422

\section{Author Bio}

Dorothy A. Sisk, Ph.D. is a professor at Lamar University in Beaumont, Texas, and Director of the Gifted Child Center. She is an international consultant focusing on gifted education, leadership and creativity development, and former Director of the U. S. Office of Gifted and Talented. Dr. Sisk was a founder and first President of the American Creativity Association, and founder and President of the World Council for Gifted and Talented Children, serving as their executive administrator, and editor of Gifted International (1980-1990). She is author and co-author of 13 books and numerous chapters and articles. 